\title{
Development of a Role Model for the Use of Smart Home Based Data in Medical Care
}

\author{
Isabel RICHTER ${ }^{\mathrm{a}, 1}$, Corinna MIELKE ${ }^{\mathrm{a}}$ and Reinhold HAUX ${ }^{\mathrm{a}}$ \\ ${ }^{a}$ Peter L. Reichertz Institute for Medical Informatics of TU Braunschweig and \\ Hannover Medical School, Braunschweig, Germany
}

\begin{abstract}
Smart home systems create new opportunities for patient care. In this paper, a role model is created for the different groups of people involved in the care process of an occupant. Based on a systematic literature review seven roles were identified. A second literature review deals with the topic Feedback of Smart Home Systems. Combining both reviews visualization proposals were created and are presented for two of the roles. The role model is adapted to German health system but could be transformed for different countries. To confirm the results an evaluation of role model and visualization proposal should be done in collaboration with possible users of smart homes.
\end{abstract}

Keywords. Smart Home, Role Model, Health Enabling Technologies, Ambient Assisted Living, Feedback, Visualization

\section{Introduction}

"Smart homes can help people monitor their health status and overall mobility." [1] Combining this statement by van Hoof et al. with the interest in data of smart home systems for different groups of people who are involved in care of an occupant [2] the implementation of a role model seems to be reasonable. This work refers to a research flat called Halberstadtstraße in Braunschweig, Germany implemented by the Peter L. Reichertz Institute [3]. Therefore, groups of people who are potential users of such smart home systems are identified conducting a systematic literature review about the topic Role Models in Medicine (RM). Subsequently roles are considered in detail to include or exclude them to the role model.

In order for conclusions to be drawn from the data, they must first be presented appropriately for the viewer [4]. To get an overview, which type of presentation of smart home data could be appropriate for different roles, a systematic literature review about the topic Feedback from Smart Home Systems (FSH) is conducted additionally. Based on these results a proposal for visualization is created. The aim of this paper is to introduce the developed role model together with corresponding visualization proposals.

\footnotetext{
${ }^{1}$ Corresponding Author, Isabel Richter, Peter L. Reichertz Institute for Medical Informatics, TU Braunschweig and Hannover Medical School, Mühlenpfordtstr. 23, 38106 Braunschweig, Germany; E-mail: isabel.richter@plri.de.
} 


\section{Methods}

Two independent literature reviews oriented by PRISMA-Statement [5] were conducted because a combination of both topics led to no results. After a few test researches PubMed [6] and IEEE Xplore [7] were searched in May 2020 using ("access control" OR authentication OR authorization OR privacy) AND (medicine OR medical OR health\$care OR health) AND ("role based" OR RBAC OR "role definition" OR "role specific") AND (FROM 2005 TO 2020) AND IN (English OR German) as search term for the topic RM and (feedback OR visuali* OR monitoring [Title] OR "web based" OR smartphone OR tablet OR "mobile application") AND ("smart home" OR "ambient assisted living”) AND (FROM 2005 TO 2020) AND IN (English OR German) as search term for the topic FSH.

Searching literature about RM and FSH resulted in 583 (RM: 105 / FSH: 478) papers in PubMed and 295 (RM: 151 / FSH: 144) in IEEE. After removing duplicates 867 (RM: 252 / FSH: 615) papers were screened in three steps: by title, by abstract and by full text. Thereby 820 (RM: 237 / FSH: 583) papers were excluded by means of exclusion criteria (RM: no human medicine, no role model, technical roles, and no role definition / FSH: no feedback, no smart home, control unit, user feedback, alarm, presentation for study purposes, and presentation not described). Thus 47 (RM: 15 / FSH: 32) papers were identified for further consideration. The related references can be found in [8].

\section{Results}

\subsection{Role Model}

Screening these papers with respect to RM, no general role model could be identified for human medicine, only different roles. Generalizing these roles results in the following list of potential user groups: administrator, patient, relative, nurse, physician, emergency staff, insurance, administrative staff, healthcare institution, and pharmacist.

The focus of data of smart home systems is in living ambient of occupants. A requirement of roles is that data from the smart home system contribute to decision-making and realization in specific task areas of the roles.

A role model including seven roles was developed based on literature results: occupant, relative, nurse, physician, emergency staff, administrator, and support and maintenance service.

In Germany, a right to self-determination with regard to information and personal data is constitutional [9]. With this respect a role occupant is necessary. In addition, there could be a personal interest. In a study by Doyle et al. [2], all subjects showed interest in the data the smart home system recorded about them.

Because relatives are involved in the care of three quarters of people in need of care in Germany (2017) [10] and occupants are willing to share their data with them [2], it seems sensible to assign them the role relatives. Less than seven percent of German population is working in health professions (2017) [10]. Therefore, no medical expertise is assumed for users of the roles occupant and relative.

Additionally, in Germany 2017 relatives were supported by outpatient nursing services in one third cases of people cared at home [10]. Hygiene aspects can be derived from data of a smart home system, which could be helpful for nursing service [3]. Thus, 
a role nurse is also necessary. For this role medical expertise is assumed justified by education as a nurse.

The role physician is a result of the fact that the behavior in everyday life can bring up important information for medical care of an occupant. For example, it is known that abnormal sleep-wake rhythm can be related to psychiatric diseases like depression and schizophrenia [11,12]. Therefore, information by a smart home system about sleeping behavior could assist the physician to diagnose psychiatric diseases. Medical expertise is assumed justified by license to practice medicine.

Normally emergency staff does not need information about the occupant on a regular basis. In some cases, however, it could be helpful for staff to get access to data of the smart home system. For example, the onset of symptoms is relevant for stroke treatment [13]. Hence, emergency staff could narrow down the onset time via last recorded activity of the occupant. Thus, a role emergency staff seems reasonable. In this case intuitive visualization is especially important because time is a factor which can make the difference between life and death in the care of emergency patients [14]. Basic medical expertise is assumed.

Many older people are not used to using technology [15] and sick people have not always the opportunity to act by themselves [16]. Thus, a role administrator seems to be important. This may especially be useful in transition between self-reliance and increased need for assistance.

For the possibility to make changes to the smart home system a role with access rights which allow changes to the system is essential. For this purpose, the role model is supplemented by a role support and maintenance service.

The other roles were not included due to different reasons:

German health insurances just need limited scope of medical information of patients to perform their statutory tasks [17]. Billing of medical services are based on diagnosis and rendered services in Germany $[18,19]$. The administration staff does not need any direct information from the smart home system for this.

The term healthcare institution is very broadly formulated. It is not possible to look at a general role healthcare institution at this point because conditions and requirements depend on concrete institution.

There are smart home systems which collect data about taking medication, but they collect data via active input of the resident. As example via speech assistance systems like Amazon Alexa or apps [20]. This work focuses on systems with passive monitoring like motion or brightness sensors thus this use case is not considered. The smart home system itself does not detect parameters about medication taken and prescribed, which could be helpful for pharmacists. Systems with active input could make this possible.

\subsection{Visualization}

Screening of papers about FSH results in an overview, which types of representation of smart home data could be found in literature. A preferred use of line charts (28 papers), bar/column diagrams ( 9 papers), and text ( 7 papers) could be identified. There are also some special representations like clock plots [2] or garden mappings [21]. Connecting representation types with the individual requirements of different roles lead to a concept of a smart home system which has different interfaces for the roles. In this paper only the interfaces for emergency staff and occupant are described. During the review no paper could be found which deals with the role emergency staff and occupant is a main 
role of the role model. Considering these roles and their backgrounds, a visualization of smart home data may look like displayed in Figure 1.

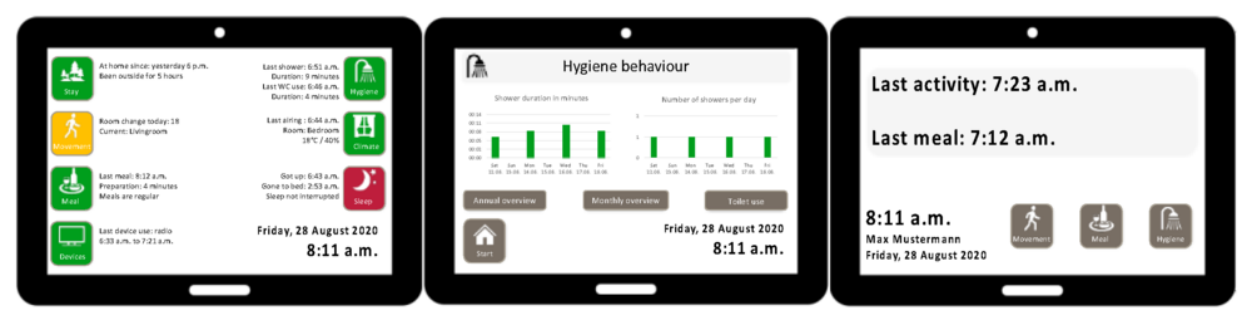

Figure 1. Visualization proposal for app based main screens for role occupant (left) and emergency staff (right) as well as a detailed screen for role occupant (middle).

\section{Discussion}

The development of the role model is based on information from a systematic literature review. This review was conducted oriented by PRISMA-Statement thus a research standard was applied. A limitation is the conduction with just one reviewer, but a consistent inclusion and exclusion should be ensured by using inclusion and exclusion criteria.

Another limitation is that representatives of the different potential user groups did not take part in the development process of the role model. Maybe roles were forgotten or wrongly included or excluded but the first version of the role model can now be used as a base for a discussion in following studies together with potential user groups. A detailed elaboration of the roles including their requirements, tasks and needed data as well as further visualizations proposals can be found in [8]. In this work also a more detailed list of references used can be found.

Inclusion and exclusion of user groups was conducted referring to German health system. From our point of view the excluded roles in Germany do not rely on information from the home environment to fulfill their respective tasks. Other countries have different structures [22] thus an adaptation seems to be necessary. This corresponds with a statement of Jayabalan and O'Daniel [23] saying that definition of a role model has to take place in practical application. Thus, this role model should be seen as a core model which can and probably has to be extended.

A defined role model could be used twice: first, for individual visualization of smart home data for different groups as presented in this work, secondly to manage access control [24].

\section{Conclusion}

In this paper a role model for medical use of smart home systems with seven roles administrator, support and maintenance service, patient, relative, nurse, physician, and emergency staff - was developed. The role model is adapted to German health system but can be used as a base for different countries. Next steps should be an evaluation of the role model and proposal of visualizations with user involvement followed by a prototypical implementation. 


\section{References}

[1] van Hoof J, Demiris G, Wouters EJM. Handbook of Smart Homes, Health Care and Well-Being. Cham, Schweiz: Springer International Publishing; c2017.

[2] Doyle J, Caprani N, Bond R. Older adults' attitudes to self-management of health and wellness through smart home data. In: 2015 9th International Conference on Pervasive Computing Technologies for Healthcare; 2015 May 20-23; Istanbul, Turkey. New Jersey, USA: IEEE; 2015. p. 129-36.

[3] Mielke C. Assistierende Gesundheitstechnologien zum Monitoring von Psychischen Erkrankungen am Beispiel der Depression [Dissertation], [Brunswick, Germany]: TU Braunschweig; 2019.

[4] Thomas BL, Crandall AS. A demonstration of PyViz, a flexible smart home visualization tool. In: 2011 IEEE International Conference on Pervasive Computing and Communications Workshops (PERCOM Workshops); 2011 March 21-25; Seattle, USA. New Jersey, USA: IEEE; 2011. p. 304-6.

[5] Moher D, Liberati A, Tetzlaff J, Altman DG. Preferred Reporting Items for Systematic Reviews and MetaAnalyses: The PRISMA-Statement. PLOS Medicine. 2009;6(7):1-6.

[6] PubMed [Internet]. Rockville Pike, USA: PubMed. c2020 [cited 2020 Nov 28]. Available from: https://pubmed.ncbi.nlm.nih.gov

[7] IEEE Xplore [Internet]. Piscataway, USA: IEEE Xplore. c2020 [cited 2020 Nov 28]. Available from: https://ieeexplore.ieee.org/Xplore/home.jsp

[8] Richter I. Rollenmodell für den Zugriff auf Daten und Auswertungen aus einer Forschungswohnung mit zugehörigem Konzept für eine App-basierte Realisierung [Bachelor thesis], [Brunswick, Germany]: TU Braunschweig; 2020. Available from: https:/cloudstorage.tubraunschweig.de/getlink/fiJufZFV6SFNLLorXbnZkk8J/.

[9] BMJV - Verbraucherportal [Internet]. Berlin, Germany: Bundesministerium der Justiz und für Verbraucherschutz; c2020. Recht an Ihren Daten; c2020 [cited 2020 Jul 13]; [about 23 paragraphs]. Available from: https:/www.bmjv.de/DE/Verbraucherportal/DigitalesTelekommunikation/ Datenschutz/Datenschutz node.html.

[10] Gulde J. Statistisches Jahrbuch 2019, Statistisches Bundesamt, Wiesbaden, Germany, 2019.

[11] Wirz-Justice A. Biologische Rhythmen und Depression. Therapeutische Umschau. 1983;40(9): 763-8.

[12] Wulff K, Gatti S, Wettstein JG, Foster RG. Sleep and circadian rhythm disruption in psychiatric and neurodegenerative disease. Nature Reviews Neuroscience. 2010 Aug;11(8):589-99.

[13] Weimar C, Weber R, Katsarava Z, Diener H-C. Thrombolyse im 3-bis 6-Stunden-Zeitfenster nach Schlaganfall. Aktuelle Neurologie. 2007;34(1):40-8. German.

[14] Luxem J et al. Rettungsdienst RS/RH, Urban \& Fischer, Munich, Germany, 2013.

[15] Bolfing A, Heinser B, Giudice G, Ritter P. Schweizer Accessibility-Studie 2016, Stiftung 'Zugang für alle', Zurich, Switzerland, 2016.

[16] Pick P. Pflegebedürftigkeit: Ein Jahr im Praxistest. Heilberufe / Das Pflegemagazin. 2018;70(1):40-1.

[17] Gesundheitswissen [Internet]. Bonn, Germany: FID Verlag GmbH; 2014. Weitergabe der Patientendaten an die Krankenkasse. 2014 Nov 27 [cited 2020 Jul 16]; [about 6 paragraphs]. Available from: https://www.gesundheitswissen.de/patientenrechte/krankenversicherungsrecht/weitergab e-derpatientendaten-an-ihre-krankenkasse/.

[18] Bundesgesundheitsministerium [Internet]. Bonn, Germany: Bundesministerium für Gesundheit; c2020. Abrechnung stationärer Krankenhausleistungen. 2016 Jan 1 [cited 2020 Dez 5]. [about 12 paragraphs]. Available from: https://www.bundesgesundheitsministerium.de/abrechnungkrankenhausleistungen.html.

[19] Bundesgesundheitsministerium [Internet]. Bonn, Germany: Bundesministerium für Gesundheit; c2020. Vergütung ambulanter ärztlicher Behandlungen. $2020 \mathrm{Jul} 13$ [cited $2020 \mathrm{Dez}$ 5]. [about 4 paragraphs]. Available from: https://www.bundesgesundheitsministerium.de/aerztliche-verguetung.html.

[20] Pfannstiel MA, Da-Cruz P, Mehlich H. Digitale Transformation von Dienstleistungen im Gesundheitswesen VI: Impulse für die Forschung, Springer Gabler, Wiesbaden, Germany, 2019.

[21] Mulvenna M, Carswell W, Mccullagh P, Wrede JCA. Visualization of data for ambient assisted living services. IEEE Communications Magazine. 2011;49(1):110-7.

[22] Wendt C. Gesundheitssysteme im internationalen Vergleich. Das Gesundheitswesen. 2006;68(10): 593-9. German.

[23] Jayabalan M, O'Daniel T. Continuous and transparent access control framework for electronic health records: A preliminary study. In: 2017 2nd International conferences on Information Technology, Information Systems and Electrical Engineering (ICITISEE); 2017 Nov 1-2; Yogyakarta, Indonesien. New Jersey, USA: IEEE; 2018. p. 165-70.

[24] Hildmann T. Umfassendes Autorisierungsmanagement [Dissertation], [Berlin, Germany]: Technische Universität Berlin; 2010. 